\title{
Studies on the impact of commonly used herbicides on beneficial soil microbes in Terai tea plantation, West Bengal, India
}

Satyajit Sarkar* and S. E. Kabir

Department of Tea Science, University of North Bengal, North Bengal University, Raja Rammohunpur, Darjeeling-734013, West Bengal, India.

Received: July 30, 2015; Revised: August 12, 2015; Accepted: August 24, 2015.

\begin{abstract}
The harmful effect of commonly used herbicides on the beneficial soil microbes in Terai tea plantation was investigated. It was found that almost all the herbicides had adverse effect on the population of beneficial microbes. 2,4-Dichlorophenoxy acetic acid was found to be most damaging herbicide.
\end{abstract}

Key Words: Beneficial soil microorganisms; Antimicrobial activity; Antifungal activity; Herbicides.

\section{Introduction}

Weeds are 'unwanted plants' in any crop field. It causes significant loss of productivity of tea which may range from $10-20 \%$ or more. It competes with host plant for water, space, nutrient, moisture and sunlight. It is estimated that weed remove about 250 $\mathrm{Kg}$ of soil nitrogen annually from tea field. There are various types of weeds and based on the longevity of weed species they are classified as Annual, Biennial and Perennial (Dutta et al., 2002).

Annuals: They are quick growers and complete their life cycle within one season. But they are most obnoxious in sense that they produce large quantity of seeds and most of the cases their growing period coincide with flush period of tea plants. ExampleAgeratum conyzoides (Kabir and Das, 2015).

Biennials: They complete their lives in two years and their flowering and seed setting usually takes place in the second year, for which low temperature is necessary. Example- Cassia sophera etc (Kabir and Das, 2015).

Perennials: They are the persistent type, which live more than two years. Their seed setting starts from 2nd year and continues every year. ExampleAxonopus compressus etc (Kabir and Das, 2015).

Some of the important weeds in tea (Kabir and Das, 2015) are,
1. Borreria latifolia
2. Mikania micrantha
3. Cynodon dactylon
4. Imperata cylindrica
5. Setaria palmifolia
6. Ageratum conyzoides
7. Sacharum spontaneum

Weeds problem in tea predominantly controlled by use of herbicides. Herbicides are categorised as follows.

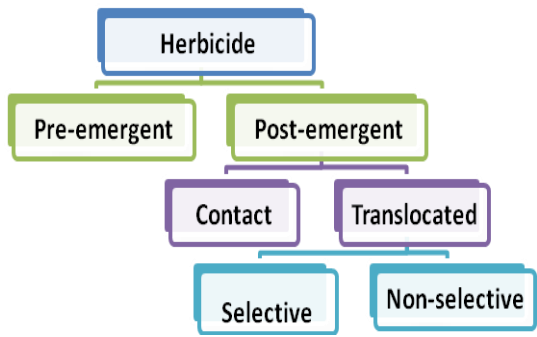

Pre-emergent herbicide: They are applied in weed free ground and they act on the weed seeds preventing them to germinate and rhizomes. Example: Simazine, Diuron and Oxyfluorfen (Dutta et al, 2002).

Post-emergent herbicides are of two types-

1. Contact: This type of herbicide starts working when it comes to the contact of the weeds. Example- Paraquat dichloride (Dutta et al., 2002).

2. Translocated: This type of herbicide starts working when it enters inside the plant tissue and control weeds by interfering with their metabolic activities (Dutta et al., 2002). It further divided in two groups-

a) Selective: This type of herbicides worked on a particular group of plants. It is very effective against broad leaf weeds. Example2,4-D (Broad leaves), Dalapon (Narrow leaves) (Dutta et al., 2002).

b) Non-selective: This type of herbicides does not work on a particular group of plants. It is very effective against small leaf weeds. Example- Glyphosate (Dutta et al., 2002).

In this experiment dalapon (Hexapon), paraquat dichloride (Gramoxone), glyphosate (Round up)

\footnotetext{
Corresponding Author

Satyajit Sarkar,

Department of Tea Science,

University of North Bengal,

P.O.: North Bengal University,

Raja Rammohanpur, Dist.: Darjeeling-734013,

West Bengal, India.
} 
and 2,4-dichoro phenoxy acetic acid (Weednash) were used (Kabir and Das, 2015). The details of those herbicides are given below-

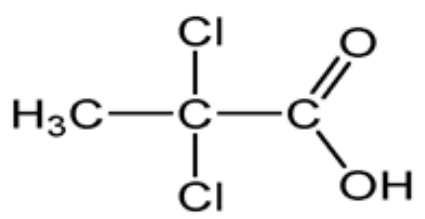

Dalapon: Dalapon is a post-emergent translocated selective herbicide.

\section{Common name: Dalapon}

Common trade name: Hexapon.

\section{Molecular structure:}

Mode of action of Dalapon: Dalapon is strong acid and protein precipitant and interferes with the synthesis of pantothenic acid, B-Vitamin used for growth. It reduces the photosynthetic action of the target plant and the leaves the target plant become yellow and curled (Dutta et al., 2002).

Paraquat dichloride: Paraquat is a contact herbicide.

Common name: Paraquat dichloride.

Common trade name: Gramoxone.

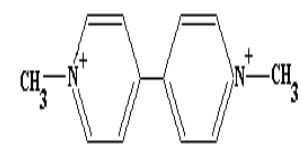

Molecular structure:

Mode of action of paraquat: This herbicide disrupts membrane integrity causing wilting, necrosis and eventual death of cells on times. High humid condition increases efficiency of paraquat. It is used to control mixed weeds (Dutta et al., 2002).<smiles>NC(NCC(=O)O)P(=O)(O)O</smiles>

Glyphosate: Glyphosate is translocated systemic herbicide.

\section{Common name: Glyphosate}

Common trade name: Round up

Chemical group: Glycine

Molecular structure:

Mode of action of glyphosate: Glyphosate inhibits aromatic amino acid biosynthetic pathway and interfere with important enzymes required for a growth or host plant. It also causes chlorosis. A rain free period of minimum 2-3 hours after spray is necessary for effective control. It is largely used to control gram and mixed weeds (Dutta et al., 2002).

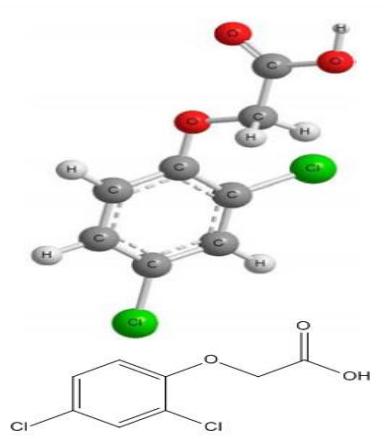

2,4-dichoro phenoxy acetic acid: 2,4-Dichoro phenoxy acetic acid is translocated selective herbicide.

\section{Common name: $2,4-\mathrm{D}$}

Common trade name: Weednash

\section{Molecular structure:}

Mode of action of 2, 4-D: 2, 4-D increases plant metabolic activity there by upsetting the balance between synthesis and use of photosynthesis causing breakdown of starch and depletion of carbohydrate reserve. Young leaves show typical curling, cresting, rolling and yellowing symptoms. It is primarily used for controlling broad leaves (Dutta et al., 2002).

Impact of herbicides on soil beneficial microorganisms:

Herbicides are toxic substances as such these chemicals reduces quantitative as well as qualitative microorganism in soil. Herbicides may interfere in the functional activity of the soil microorganism. Szeginj (1972) observed that cellulolytic activities of microorganism are affected by 2, 4-D application @ $0.25 \mathrm{ppm}$.

Anderson (1978) observed the effect of herbicides on different soil microorganism (fungi, bacteria, actinomycetes, nitrogen fixing organism phosphate solubilising microorganism.

\section{Location of the experiment:}

The experiment was conducted in section number \# D, at University of North Bengal Tea Plantation Area and the laboratory of Department of Tea Science, University of North Bengal. Geographical location: Longitude: $26^{0} 42$ '42.08' North, Latitude: 88 21'00.18' East, Elevation: 138 m AMSL. 


\section{Materials and Methods}

Location, number of bushes and area:

In section number \# D at University of North Bengal tea plantation area 24 plots were made. Each plot contained 8 bushes into each hedge and contained 2 space in between hedges. Area of the per plot is 10 square metres.

\section{Experimental design and Layout:}

There were total 4 treatments and each treatment had 6 replications.

Treatment(T1): Dalapon(Hexapon)

Treatment(T2): Paraquat dichloride (Gramoxone)

Treatment(T3): Glyphosate (Round up)

Treatment(T4): 2,4-Dichoro phenoxy acetic acid (Weednash)

The treatments were arranged in Randomised Block Design (RBD).

Figure 1: RBD design of treatments in plots

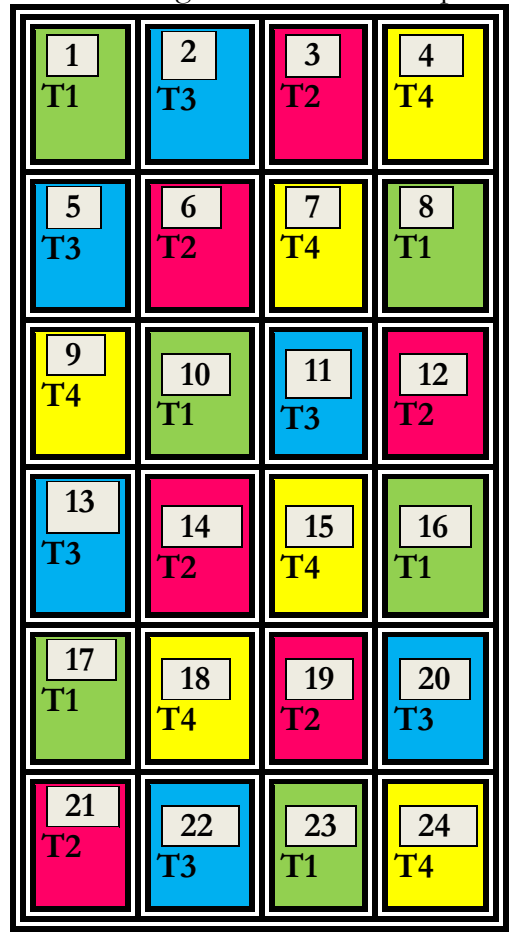

Collection of Pre-treatment soil samples: Top soil samples were collected form 2 sites in between the hedges and in between 2 tea plants from each plot.

\section{Doses of the herbicides:}

Dalapon(Hexapon)@8.75g/litre.

Paraquat dichloride (Gramoxone)@ 5 ml/2 litres.

Glyphosate (Round up)@ $10 \mathrm{ml}$ litre.

2,4-Dichoro phenoxy acetic acid (Weednash) @ 8 $\mathrm{ml} /$ litre.

\section{Spraying of the treatments:}

The treatments were sprayed according to the RBD layout in every plot.

T1: 1, 8, 10,16, 17 and 23
T2: 3, 6, 12,14, 19 and 21

T3: $2,5,11,13,20$ and 22

T4: $4,7,9,15,18$ and 24

\section{Collection of Post-treatment soil samples:}

Collected top soil samples from 2 sites in between the hedges and in between 2 tea plants from each plot.

\section{A. Methods applied in laboratory for microbial culture:}

The pre-treatments soil samples of all the replications of T1 were mixed together. Like T1 all the soil samples of $\mathrm{T} 2$, T3 and T4 were mixed separately. The soil samples of T1, T2, T3 and T4 sieved separately and kept separately. Distilled water was prepared in the distil water plant and collected in the jar. Twelve $250 \mathrm{ml}$ conical flask was taken and $100 \mathrm{ml}$ of distil water was poured in each. The mouth of the conical flask was plugged with cotton and sealed with paper and thread. Then all the conical flasks were placed into the autoclave machine for $20 \min$ @ 15 psi pressure for sterilisation.10 $\mathrm{g}$ of soil sample is taken and poured into the $100 \mathrm{ml}$ sterilised distilled water. Shaken it for $15 \mathrm{~min}$ in Shaker Machine. From that sample 1 $\mathrm{ml}$ was taken with the help of micro pipette and poured into the $100 \mathrm{ml}$ sterilised distilled water for dilution. This was done at Laminar Flow Machine to avoid contamination. Shaken it for $15 \mathrm{~min}$ in Shaker Machine. From that sample $1 \mathrm{ml}$ was taken with the help of micro pipette and poured into the $100 \mathrm{ml}$ sterilised distil water for $10^{3}$ dilution. This was done at Laminar Flow Machine to avoid contamination. Shaken it for $15 \mathrm{~min}$ in Shaker Machine. From that sample $1 \mathrm{ml}$ was taken with the help of micro pipette and poured into the $100 \mathrm{ml}$ sterilised distil water for $10^{5}$ dilution. This was done at Laminar Flow Machine to avoid contamination. After every transfer of soil samples to another dilution micro pipette was cleaned with alcohol. In each soil samples T1, T2, T3 and T4 done this process separately (Subba Rao, 1981).

Prepared the selective cultural media for the selective microorganisms. Ashby's Mannitol Agar for Azotobacter, Yeast Mannitol Agar for Rhizobium, Azospirilium Medium for Azospirillum, Pikovskaya's Agar for Phosphate solubilising microorganism, Nutrient Agar for Total bacteria, Rose Bengal Chloramphenicol

Agar for Fungi. Three replications had been made for each selective medium of each treatment. All the petri dishes were labelled properly. $1 \mathrm{ml}$ of soil sample $\left(10^{5}\right.$ dilutions for all cultural medium and $10^{3}$ dilution for RBC) of T1 was put into the tagged petridish and after that small amount of particular selective cultural medium was put into it and spread uniformly. Three replication of each medium of particular treatment was made. All the process was 
done in Laminar Flow Machine in front of a sprit lamp to avoid contamination. After every culture of treatments, the micro pipette was cleaned with alcohol to avoid contamination. After that it was kept for culture on the Laminar Flow (Subba Rao, 2012). Similarly, T2, T3 and T4 soil samples were cultured. After 7 the days of treatment soil sample was collected, diluted and cultured using same methods.

\section{B. Carbon-di-oxide evolution test of the sieving soil samples:}

Microbial activity is determined by the carbon-dioxide evolution test. Pre-treatment sieving soil samples were kept for air drying. 3 replications (A, $\mathrm{B}$ and $\mathrm{C}$ ) of each treatment soil was taken. Marked the plastic jar as per treatment and treatment and replication. $100 \mathrm{~g}$ of air dried sieving soil sample is weighted and poured into the specified plastic jar. Added required amount of water. $10 \mathrm{ml} \mathrm{KOH}$ was put into the injection vial and hanged it into the soil with the help of thread and sealed the jar by putting the cap of the jar and with wide cello tape. After 24 hours the $\mathrm{KOH}$ was titrated with $\mathrm{HCl}$ using Phenopthalin as an indicator. Washed the conical flask after testing of every sample. Calculated the carbon-di-oxide evolution all pre-treatment sieving soil samples (T1, T2, T3 and T4) by using formula (Subba Rao, 2012). Same method was applied to calculate carbon-di-oxide evolution of the posttreatment sieving soil samples (T1, T2, T3 and T4).

\section{Results and Discussion \\ Microbial culture:}

The radius of the Petri dish was $90 \mathrm{~mm}$. So, the area of the Petri dish was-

$$
\pi r^{2}=\left(\frac{22}{7}\right) X(9)^{2} \mathrm{~cm}^{2}=254.57^{\mathrm{cm}^{2}}
$$

The number of the formation of colonies on that particular area in different selective media was counted. The mean of the replication A, B and C for each selective mediums culture was taken. Total 72 X $2=144$ cultures (pre-treatment and posttreatment) were prepared. $1^{\text {st }}$ observation was taken after 24 hours of the culture and $2^{\text {nd }}$ observation after 72 hours in case of pre-treatment and posttreatment culture.

Round white glistening and raised colonies were observed as Azotobacter or nitrogen fixing bacteria (ASBY). Raised, round, light pinkish colonies were considered as Rhizobium (YEMA). There is no Azospirillum in soil (AZO). Microbial colonies without hallo zone (PSM). Round and spindle shaped cream and yellow coloured nice bacterial colonies observed (NA). All fungal population observed (RBC).

The colonies are very small so they were not identifiable. In PSM there was huge population of Phosphate solubilising microorganisms. All the microbial organisms decreased compared to the pre-treatment soil sample cultures.

Table 1: Pre-treatment soil cultures at $1^{\text {st }}$ observation

\begin{tabular}{|c|c|c|c|c|c|c|c|c|c|}
\hline & \multirow{2}{*}{$\begin{array}{l}\text { S. No. } \\
\text { RC }\end{array}$} & \multicolumn{2}{|c|}{ T1 } & \multicolumn{2}{|c|}{ T2 } & \multicolumn{2}{|c|}{ T3 } & \multicolumn{2}{|c|}{ T4 } \\
\hline & & TC & $\mathbf{M}$ & TC & M & TC & M & TC & M \\
\hline \multirow{3}{*}{ ASBY } & A & 8 & 7.67 & 6 & & 7 & 6.33 & 11 & 7.33 \\
\hline & B & 6 & $\approx$ & 4 & 5 & 9 & $\approx$ & 5 & $\approx$ \\
\hline & C & 9 & 8 & 5 & & 3 & 6 & 6 & 7 \\
\hline \multirow{3}{*}{ YEMA } & A & 11 & 6.67 & 3 & 5.67 & 6 & 7.33 & 11 & \\
\hline & B & 3 & $\approx$ & 8 & $\approx$ & 9 & $\approx$ & 6 & 9 \\
\hline & C & 6 & & 6 & & 7 & & 10 & \\
\hline \multirow{3}{*}{$\mathrm{AZO}$} & A & 0 & & 0 & & 0 & & 0 & \\
\hline & B & 0 & 0 & 0 & 0 & 0 & 0 & 0 & 0 \\
\hline & C & 0 & & 0 & & 0 & & 0 & \\
\hline \multirow{3}{*}{ PSM } & A & 13 & & 18 & 12.33 & 8 & 9.67 & 13 & \\
\hline & B & 20 & 14 & 12 & $\approx$ & 12 & $\approx$ & 14 & 12 \\
\hline & C & 9 & & 7 & 12 & 9 & 10 & 9 & \\
\hline \multirow{3}{*}{$\mathrm{NA}$} & A & 2 & & 3 & & 4 & 2.33 & 2 & \\
\hline & B & 0 & 1 & 0 & $\approx$ & 0 & $\approx$ & 4 & $\approx$ \\
\hline & C & 1 & & 2 & 2 & 3 & 2 & 14 & 7 \\
\hline \multirow{3}{*}{$\mathrm{RBC}$} & A & 51 & & 30 & & 52 & & 190 & \\
\hline & B & 45 & $\begin{array}{c}57.33 \\
\approx\end{array}$ & 37 & $\begin{array}{c}34.67 \\
\approx\end{array}$ & 66 & $\begin{array}{c}59.33 \\
\quad \approx\end{array}$ & 133 & $\begin{array}{c}162.33 \\
\approx\end{array}$ \\
\hline & C & 76 & 57 & 37 & 35 & 60 & 59 & 164 & 162 \\
\hline
\end{tabular}

$\mathrm{RC}=$ Replication, $\mathrm{TC}=$ Total colony count, $\mathrm{M}=$ Mean

The colonies were very small so they were not identifiable. In PSM there was no hallo zone. 
Table 2: Pre-treatment soil cultures at $2^{\text {nd }}$ observation

\begin{tabular}{|c|c|c|c|c|c|c|c|c|c|}
\hline \multirow{2}{*}{\multicolumn{2}{|c|}{ S.No. RC }} & \multicolumn{2}{|c|}{ T1 } & \multicolumn{2}{|c|}{ T2 } & \multicolumn{2}{|c|}{ T3 } & \multicolumn{2}{|c|}{ T4 } \\
\hline & & TC & $\mathbf{M}$ & TC & $\mathbf{M}$ & TC & M & TC & $\mathbf{M}$ \\
\hline \multirow{3}{*}{ ASBY } & A & 83 & & 53 & 55.33 & 89 & 86.67 & 108 & 82.67 \\
\hline & B & 69 & 81 & 56 & $\approx$ & 93 & $\approx$ & 77 & $\approx$ \\
\hline & C & 91 & & 57 & 55 & 78 & 87 & 63 & 83 \\
\hline \multirow{3}{*}{ YEMA } & A & 57 & & 41 & & 24 & 30.33 & 60 & \\
\hline & B & 33 & 42 & 20 & 29 & 28 & $\approx$ & 57 & 63 \\
\hline & C & 36 & & 26 & & 39 & 30 & 72 & \\
\hline \multirow{3}{*}{ AZO } & A & 0 & & 0 & & 0 & & 0 & \\
\hline & B & 0 & 0 & 0 & 0 & 0 & 0 & 0 & 0 \\
\hline & C & 0 & & 0 & & 0 & & 0 & \\
\hline \multirow{3}{*}{ PSM } & A & 24 & 25.3 & 39 & & 28 & & 46 & \\
\hline & B & 25 & 3 & 21 & $\begin{array}{l}30.67 \\
\approx\end{array}$ & 29 & $\begin{array}{l}29.67 \\
\approx\end{array}$ & 39 & $\begin{array}{l}39.33 \\
\approx\end{array}$ \\
\hline & C & 27 & $\approx$ & 23 & 31 & 32 & 30 & 33 & 39 \\
\hline \multirow{3}{*}{ NA } & A & 2 & 9.67 & 24 & 38.67 & 87 & 62.67 & 57 & 52.67 \\
\hline & B & 15 & $\approx$ & 49 & $\approx$ & 48 & $\approx$ & 62 & $\approx$ \\
\hline & C & 12 & 10 & 43 & 39 & 53 & 63 & 39 & 53 \\
\hline \multirow{3}{*}{$\mathrm{RBC}$} & A & 80 & & 100 & 106.33 & 108 & 100.33 & 207 & \\
\hline & B & 83 & 81 & 107 & $\approx$ & 101 & $\approx$ & 186 & 195 \\
\hline & C & 80 & & 112 & 106 & 92 & 101 & 192 & \\
\hline
\end{tabular}

$\mathrm{RC}=$ Replication, $\mathrm{TC}=$ Total colony count, $\mathrm{M}=$ Mean

Table 3: Post-treatment soil cultures at $1^{\text {st }}$ observation

\begin{tabular}{|c|c|c|c|c|c|c|c|c|c|}
\hline \multirow{2}{*}{\multicolumn{2}{|c|}{ S. No. RC }} & \multicolumn{2}{|c|}{ T1 } & \multicolumn{2}{|c|}{ T2 } & \multicolumn{2}{|c|}{ T3 } & \multicolumn{2}{|c|}{ T4 } \\
\hline & & TC & $\mathbf{M}$ & TC & $\mathbf{M}$ & TC & $\mathbf{M}$ & TC & $\mathbf{M}$ \\
\hline \multirow{3}{*}{ ASBY } & A & 7 & \multirow{3}{*}{5} & 3 & 2.67 & 33 & 21.67 & 8 & \multirow{3}{*}{8} \\
\hline & B & 3 & & 2 & $\approx$ & 22 & $\approx$ & 9 & \\
\hline & C & 5 & & 3 & 3 & 10 & 22 & 7 & \\
\hline \multirow{3}{*}{ YEMA } & A & 7 & \multirow{3}{*}{5} & 3 & \multirow{3}{*}{$\begin{array}{c}7.33 \\
\approx \\
7\end{array}$} & 19 & \multirow{3}{*}{$\begin{array}{c}13.67 \\
\approx \\
14\end{array}$} & 5 & \multirow{3}{*}{$\begin{array}{c}9.33 \\
\approx \\
10\end{array}$} \\
\hline & B & 3 & & 9 & & 17 & & 11 & \\
\hline & C & 5 & & 10 & & 5 & & 12 & \\
\hline \multirow{3}{*}{$\mathrm{AZO}$} & A & 0 & \multirow{3}{*}{0} & 0 & \multirow{3}{*}{0} & 0 & & 0 & \multirow{4}{*}{0} \\
\hline & B & 0 & & 0 & & 0 & 0 & 0 & \\
\hline & C & 0 & & 0 & & 0 & & 0 & \\
\hline \multirow{3}{*}{ PSM } & A & HP & \multirow{3}{*}{ HP } & HP & & HP & & HP & \\
\hline & B & HP & & HP & \multirow{2}{*}{ HP } & HP & \multirow{2}{*}{ HP } & HP & \multirow[t]{2}{*}{$\mathrm{HP}$} \\
\hline & C & HP & & HP & & HP & & HP & \\
\hline \multirow{3}{*}{ NA } & A & 0 & \multirow{3}{*}{0} & 1 & \multirow{3}{*}{$\begin{array}{c}0.67 \\
\approx \\
1\end{array}$} & 4 & \multirow{3}{*}{$\begin{array}{c}5.33 \\
\approx \\
5\end{array}$} & 0 & \multirow{3}{*}{$\begin{array}{c}1.33 \\
\approx \\
1\end{array}$} \\
\hline & B & 0 & & 0 & & 4 & & 2 & \\
\hline & C & 0 & & 1 & & 8 & & 2 & \\
\hline \multirow{3}{*}{$\mathrm{RBC}$} & A & 17 & \multirow{3}{*}{$\begin{array}{c}20.33 \\
\approx \\
20\end{array}$} & 31 & \multirow{3}{*}{$\begin{array}{c}35.67 \\
\approx \\
36\end{array}$} & 46 & 48.67 & 50 & 56.67 \\
\hline & B & 21 & & 49 & & 57 & $\approx$ & 53 & \multirow{2}{*}{$\underset{57}{\approx}$} \\
\hline & C & 23 & & 27 & & 43 & 49 & 67 & \\
\hline
\end{tabular}

$\mathrm{RC}=$ Replication, $\mathrm{TC}=$ Total colony count, $\mathrm{M}=$ Mean, $\mathrm{HP}=$ Huge population

Table 4: Post-treatment soil cultures at $2^{\text {nd }}$ observation

\begin{tabular}{|c|c|c|c|c|c|c|c|c|c|}
\hline \multirow{3}{*}{ S. No. of 1} & & \multicolumn{2}{|c|}{ T1 } & \multicolumn{2}{|c|}{ T2 } & \multicolumn{2}{|c|}{ T3 } & \multicolumn{2}{|c|}{ T4 } \\
\hline & & TC & $\mathbf{M}$ & TC & $\mathbf{M}$ & TC & M & TC & $\mathbf{M}$ \\
\hline & A & 9 & 7.67 & 8 & 6.33 & 41 & 33.33 & 26 & 17.67 \\
\hline \multirow[t]{3}{*}{ ASBY } & B & 4 & $\approx$ & 3 & $\approx$ & 40 & $\approx$ & 14 & $\approx$ \\
\hline & C & 10 & 8 & 8 & 6 & 19 & 33 & 13 & 18 \\
\hline & A & 15 & & 7 & 12.67 & 37 & 22.67 & 11 & \\
\hline \multirow[t]{3}{*}{ YEMA } & B & 9 & 11 & 13 & $\approx$ & 23 & $\approx$ & 22 & \\
\hline & C & 9 & & 18 & 13 & 8 & 23 & 24 & 19 \\
\hline & A & 0 & & 0 & & 0 & & 0 & \\
\hline \multirow[t]{3}{*}{ AZO } & B & 0 & & 0 & & 0 & & 0 & \\
\hline & C & 0 & 0 & 0 & 0 & 0 & 0 & 0 & 0 \\
\hline & A & 2 & 1.67 & 1 & & 6 & 6.33 & 3 & 1.33 \\
\hline \multirow{3}{*}{ PSM } & B & 0 & $\approx$ & 0 & & 4 & $\approx$ & 0 & $\approx$ \\
\hline & C & 3 & 2 & 2 & 1 & 9 & 6 & 1 & 1 \\
\hline & A & 6 & 6.67 & 2 & 3.67 & 22 & 21.33 & 12 & 13.33 \\
\hline \multirow[t]{2}{*}{ NA } & B & 7 & $\approx$ & 3 & $\approx$ & 14 & $\approx$ & 13 & $\approx$ \\
\hline & C & 7 & 7 & 6 & 4 & 28 & 21 & 15 & 13 \\
\hline \multirow{5}{*}{$\mathrm{RBC}$} & & & 25.33 & & & & 53.67 & & 66.67 \\
\hline & A & 23 & $\approx$ & 37 & 42 & 48 & $\approx$ & 57 & $\approx$ \\
\hline & & & 25 & & & & 54 & & 67 \\
\hline & B & 24 & & 52 & & 65 & & 66 & \\
\hline & C & 29 & & 37 & & 48 & & 77 & \\
\hline
\end{tabular}


Round white glistening and raised colonies were counted as Azotobacter or nitrogen fixing bacteria (ASBY). Raised, round, light pinkish colonies were considered as Rbizobium (YEMA). There is no Azospirillum in soil (AZO). Microbial colonies without hallo zone (PSM). Round and spindle shaped cream and yellow coloured nice bacterial colonies observed (NA). All fungal population observed (RBC). All the microbial organisms decreased compared to the pre-treatment soil sample cultures.

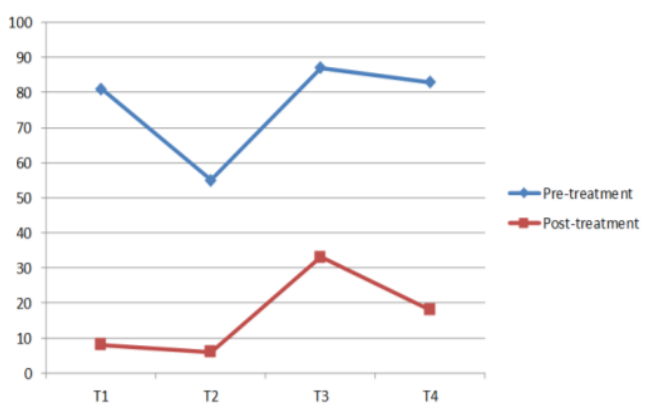

Figure 2: Comparison between the pre-treatment and post-treatment ( $2^{\text {nd }}$ observations mean number of colonies) of Azotobacter or nitrogen fixing bacteria:

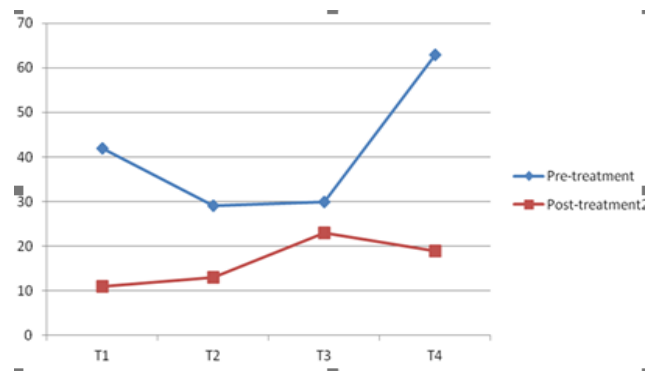

Figure 3: Comparison between the pre-treatment and post-treatment ( $2^{\text {nd }}$ observations mean number of colonies) of Rhizobium:

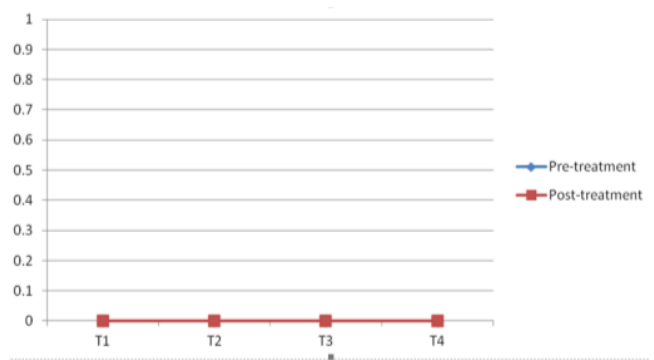

Figure 4: Comparison between the pre-treatment and post-treatment ( $2^{\text {nd }}$ observations mean number of colonies) of Azospirillum: There is no Azospirillum in the both pre and post treatment soil samples.

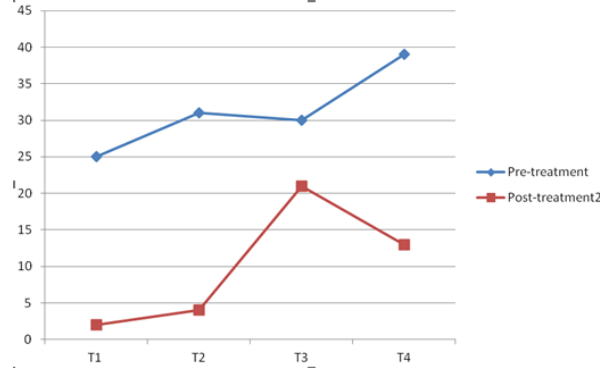

Figure 5: Comparison between the pre-treatment and post-treatment $\left(2^{\text {nd }}\right.$ observations mean number of colonies) of Phosphate Solubilising Microorganisms:

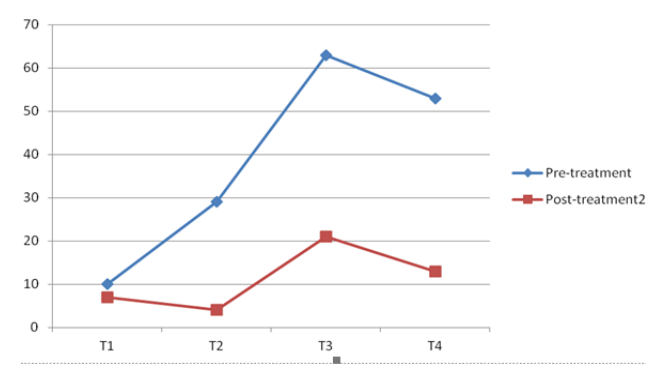

Figure 6: Comparison between the pre-treatment and post-treatment $\left(2^{\text {nd }}\right.$ observations mean number of colonies) of bacterial colonies:

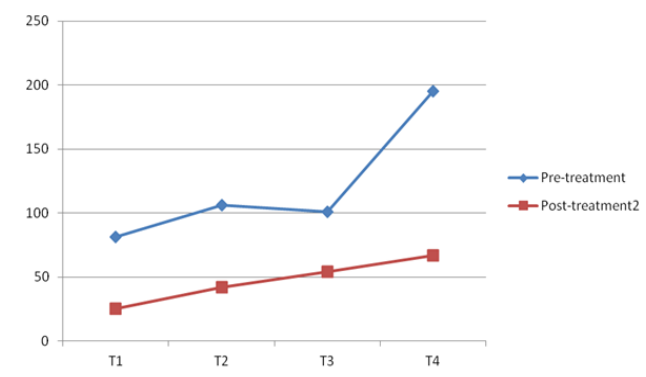

Figure 7: Comparison between the pre-treatment and post-treatment $\left(2^{\text {nd }}\right.$ observations mean number of colonies) of fungus:

2. Carbon-di-oxide evolution test of the soil samples:

We know, $\mathrm{HCl}(0.1 \mathrm{~N})=\mathrm{KOH}(0.1 \mathrm{~N})$

$2 \mathrm{KOH}+\mathrm{CO}_{2} \uparrow=\mathrm{K}_{2} \mathrm{CO}_{3}+\mathrm{H}_{2} \mathrm{O}$

Molecular weight of $\mathrm{CO}_{2}$ :

$\mathrm{C}=12 \mathrm{mg}, \mathrm{O}=16 \mathrm{mg}$.

So, molecular weight of $\mathrm{CO}_{2}=12+(16 \times 2) \mathrm{mg}=44 \mathrm{mg}$

So, $2 \mathrm{KOH}+44 \mathrm{mg}=\mathrm{K}_{2} \mathrm{CO}_{3}+\mathrm{H}_{2} \mathrm{O}$

$2 \mathrm{KOH}=44 \mathrm{mg}$ of $\mathrm{CO}_{2}$

So, $1 \mathrm{KOH}=22 \mathrm{mg}$ of $\mathrm{CO}_{2}$

We know, $\mathrm{HCl}(1 \mathrm{~N})=\mathrm{KOH}(1 \mathrm{~N})$

So, the evolution of $\mathrm{CO}_{2}=$ Excess $\mathrm{HCl}$ in titration $\times 2.2$ $\mathrm{mg} \mathrm{CO} / 100 \mathrm{~g}$ soil/24 hours.

Table 5: $\mathrm{CO}_{2}$ evolution in pre-treatment soil samples:

\begin{tabular}{|c|c|c|c|c|c|}
\hline \multirow[b]{2}{*}{ Soil samples } & \multicolumn{3}{|c|}{ Replication } & \multirow[b]{2}{*}{ Mean } & \multirow[b]{2}{*}{$\begin{aligned} \text { Evolution of } \mathrm{CO}_{2}= & \text { Excess } \mathrm{HCl} \text { in titration } \times 2.2 \mathrm{mg} \mathrm{CO} / \\
& 100 \mathrm{~g} \text { soil } / 24 \text { hours }\end{aligned}$} \\
\hline & $\begin{array}{c}\mathbf{A} \\
(\mathrm{ml})\end{array}$ & $\begin{array}{c}\mathbf{B} \\
(\mathrm{ml})\end{array}$ & $\underset{(\mathrm{ml})}{\mathbf{C}}$ & & \\
\hline T1 & 2.0 & 3.3 & 1.9 & 2.40 & 5.28 \\
\hline $\mathrm{T} 2$ & 1.9 & 3.4 & 1.9 & 2.40 & 5.28 \\
\hline $\mathrm{T} 3$ & 2.5 & 2.6 & 2.6 & 2.57 & 5.65 \\
\hline $\mathrm{T} 4$ & 2.6 & 2.4 & 2.5 & 2.50 & 5.50 \\
\hline
\end{tabular}


Table 6: $\mathrm{CO}_{2}$ evolution in post-treatment soil samples:

\begin{tabular}{|c|c|c|c|c|c|}
\hline \multirow[b]{2}{*}{ Soil samples } & \multicolumn{3}{|c|}{ Replication } & \multirow[b]{2}{*}{ Mean } & \multirow[b]{2}{*}{$\begin{aligned} \text { Evolution of } \mathrm{CO}_{2}= & \text { Excess } \mathrm{HCl} \text { in titration x } 2.2 \mathrm{mg} \mathrm{CO} / \\
& 100 \mathrm{~g} \text { soil } / 24 \text { hours }\end{aligned}$} \\
\hline & $\begin{array}{c}\text { A } \\
(\mathrm{ml})\end{array}$ & $\begin{array}{c}\text { B } \\
(\mathrm{ml})\end{array}$ & $\begin{array}{c}\mathrm{C} \\
(\mathrm{ml})\end{array}$ & & \\
\hline T1 & 2.2 & 2.0 & 2.3 & 2.17 & 4.71 \\
\hline T2 & 2.1 & 2.1 & 2.1 & 2.10 & 4.62 \\
\hline T3 & 2.0 & 1.9 & 1.9 & 1.93 & 4.25 \\
\hline $\mathrm{T} 4$ & 2.2 & 2.0 & 2.2 & 2.13 & 4.67 \\
\hline
\end{tabular}

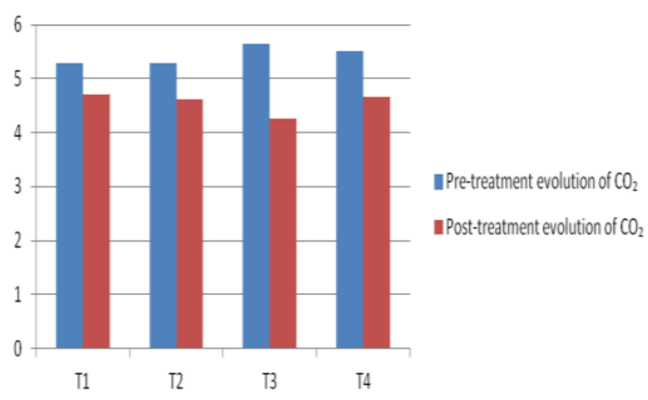

Figure 8: Comparison between pre-treatment and post-treatment soil samples evolution of $\mathrm{CO}_{2}$ (Mean numbers):

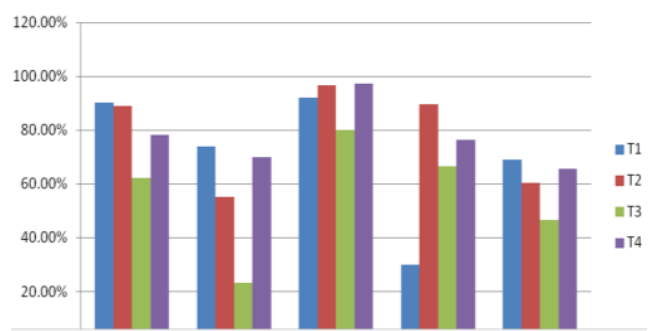

Figure 9: Comparison between the pre-treatment and post-treatment (2nd observation) decreasing percentage of the beneficial soil microbe's colonies:

\section{Conclusion}

It was observed that there was no Azospirillum population in the samples both pre-treatment and post-treatment. Dalapon (Hexapon) mostly decreases the population of Azotobacter, Rhizobium, Phosphate Solubilising microorganism and Fungi. Paraquat dichloride (Gramoxone) mostly decreases the population of Azotobacter, Phosphate Solubilising microorganism and fungi. Glyphosate (Round up) mostly decreases the population of Azotobacter, total bacteria and fungi. 2,4-Dichoro phenoxy acetic acid (Weednash) mostly decreases the population of Azotobactor, Rhizobium, Phosphate Solubilising microorganism, total bacteria and fungi. So, the 2,4-Dichoro phenoxy acetic acid (Weednash) is more harmful than Dalapon (Hexapon), Paraquat dichloride (Gramoxone) and Glyphosate (Round up) to the beneficial soil microbes in Terai tea plantation. Estimated the soil respiration of pre-treatment and post-treatment soil samples by calculating the evolution of $\mathrm{CO}_{2}$. It was observed that the applied herbicides decreased the evolution of $\mathrm{CO}_{2}$ upto $0.5-1.5 \mathrm{mg} \mathrm{CO}_{2} / 100 \mathrm{~g}$ soil/24 hours in each treatment.

It was observed that Dalapon decreased Azotobacter 90.12\%, Rhizobium 73.80\%, Phosphate solubilising micro organism 92\%, Total bacteria 30\%, Fungi population $69.13 \%$. Paraquat dichloride decreased Arotobacter $89.09 \%$, Rhizobium 55.17\%, Phosphate solubilising micro organism $96.77 \%$, Total bacteria $89.74 \%$, Fungi population $60.38 \%$. Glyphosate decreased Azotobacter 62.09\%, Rhizobium 69.84\%, Phosphate solubilising micro organism $80 \%$, Total bacteria $66.67 \%$, Fungi population $46.53 \%$. 2,4Dichoro phenoxy acetic acid decreased Azotobacter 78.31\%, Rhizobium 69.84\%, Phosphate solubilising micro organism $97.43 \%$, Total bacteria $76.36 \%$, Fungi population $65.64 \%$.

\section{References}

1. Anderson, J. R. Pesticide effects on Non-Target Soil Microorganism. In I.R. Hill and S.J.L. Wright (eds.), Pesticide Microbiology. (1978). 313 - 533. English.

2. Dutta, A. K., Kotoky, B. and Bora, K. Tea weeds and their control. Notes on Field Management. Tea Research Association, Tocklai Experimental station. (2002). 141 156. English.

3. Kabir, S. E. and Das, A. P. Soil science and nutrients. Tea cultivation in the plains of North East India. (2015). 27 61. English.

4. Subba Rao, N. S. Biofertilizer in agriculture. Oxford and IBH Publication. (1981). 146-147. English.

5. Subba Rao, N. S. Soil Microbiology (Fourth edition of soil microorganisms and plant growth). (2012).1 - 404. English.

6. Szeginj. Effect of few herbicides on the decomposition of cellulose. Symp. Biol. Hung II. (1972). 349 - 354. English.

\section{Cite this article as:}

Satyajit Sarkar and S. E. Kabir. Studies on the impact of commonly used herbicides on beneficial soil microbes in Terai tea plantation, West Bengal, India. Annals of Plant Sciences 5.1 (2016): 1254-1260. 